\title{
A new paradigm of urban development: envisioning sustainable futures in Qatar
}

\author{
Hatem Galal A. Ibrahim \\ Department of Architecture and Urban Planning, \\ College of Engineering, Qatar University, Qatar (on leave from: \\ Department of Architecture in Mataria, Helwan University, Egypt)
}

\begin{abstract}
In the past few years and as a result of the dramatic increase in national income that has accompanied the development of the oil industry, Qatar has undergone immense changes in its social, economic and physical environments. In less than half a century, the country has been transformed from a nomadic and subsistence farming economy into a modern urban/industrial society with a per capita income that is considered one of the highest worldwide. As a result, the demographics of the society have become more global and contemporary and international values and attitudes have impacted the existing cultural and architectural patterns. Qatari architectural trends have become increasingly contemporary and completely detached from the traditional ones that reflect the country's identity. Doha, the capital, has recently witnessed the resurgence of the discourse on Islam as a cultural identity. Qatar's attractiveness today is generated from its modernized architectural patterns and styles that balance traditionism and modernism. Many of the newly designed buildings are strictly reproducing the Qatari traditional elements and styles.

This paper focuses on understanding the relationship between culture and identity in Qatar. Traditional places where major festivals and cultural social activities take place, within the social and urban fabric of culturally diverse cities. The paper investigates this idea as an approach of maintaining the principles of traditional Qatari architecture while taking advantage of the introduced modern technology. The paper also calls for integrating the identity of the place within the contemporary urban environment of old cities.
\end{abstract}

Keywords: Qatari architecture language, contemporary architecture, sustainable development, urban environment, cultural identity. 


\section{Introduction}

Traditional architecture is being recognised as the true bastion of rationality. There is nothing superfluous in traditional architecture. The solutions proposed are the result of centuries of empiricism. At the same time, its relationship with its setting is more appropriate, as it is the source of life for all those living in it. The setting is carefully preserved and transformed with extreme sensitivity, never forgetting that it will have to be passed on to future generations.

In the past, when the building envelope was the main element man used to protect himself from a harsh climate, he had to depend on passive energy and natural resources, such as sun, wind and earth. Passive energy involves the use of natural energy sources for environmental, healthy and economical reasons in our buildings. Traditional architecture, in the Arab world, represents a living witness for the suitability of this architecture to the local environment, which incorporated the essence of sustainable architecture.

Adham [1] states that the Architecture of Qatar is exemplified by its capital city Doha, which has changed significantly from a small town with no more than 20,000 inhabitants in the early 1950 s to a global city and a regional economic hub with more than 1.7 million inhabitants in 2010 [2]. Doha's rapid pace of urbanization is depicted in Figure 1 below, which clearly shows the significant expansion of its built agglomeration over the past 65 years, from approximately 1.3 square kilometers in the late 1940 s to over 200 square kilometers in 2010 [2, 3].

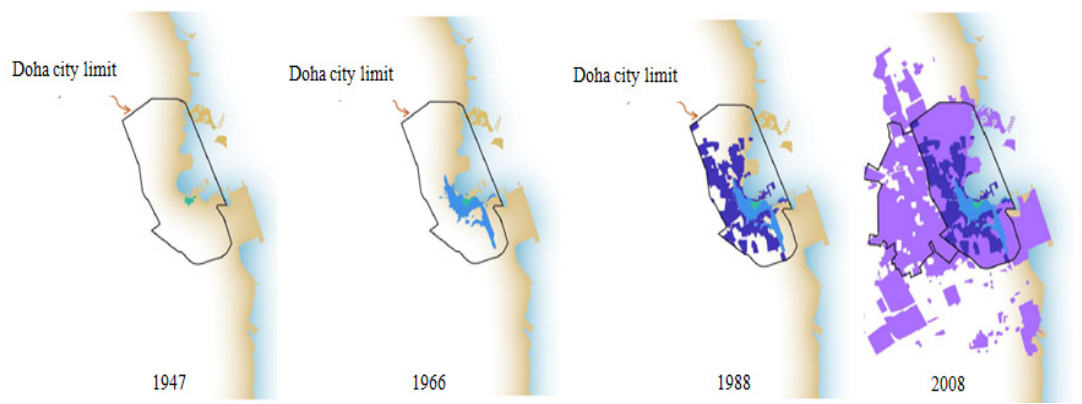

Figure 1: $\quad$ Doha's urban growth 1947-2008.

The contemporary architecture of Qatar is a result of a range of contemporary urban dynamics that are inextricably linked to complex and interconnected forces and processes of economic transformation, cultural restructuring, and globalization. These dynamics involve all the key components of urban systemshuman, natural, and built that significantly differ from the dynamics and processes that governed urban growth patterns of Doha during the second half of the $20^{\text {th }}$ century.

Until the early 1990s, Doha's urban growth patterns progressed at a relatively slow rate through state-funded infrastructure, services, and housing projects. The slow rate of urban development was widely attributed to the country's relatively 
unstable labor market [3]. The references attribute this instability to the country's oil-based economy in which the hiring of construction and expatriate workers correlated with the country's fluctuating oil revenues $[1,4]$.

Since the late 1990s, Doha's urban growth has been progressing at a much faster rate, which is attributed to a transition from oil-based toward a competitive and more complex globalized economy [5]. This transition, despite the strong dependence of government's spending on oil revenues, has made Qatar's rapid growth the fastest in the world during the 2000s. The transition resulted in substantial domestic investment in infrastructure and promoted diversification in the country's labor market, including employment in entrepreneurship, education and event tourism sectors $[2,6]$. As a result, Doha begun to emerge as a global center for media, education, culture and finance through huge investments and several initiatives such as the Al Jazeera Channel, the Doha Economic Zone, the Education City, Qatar Foundation for Education, Science and Community Development and the "Pearl Island" reclamation project. This was accompanied by a construction boom that erected skyscrapers, sport facilities, shopping malls, gated communities and iconic museums and libraries.

As a result of the dramatic increase in national income that has accompanied the development of the oil industry, Qatar has undergone immense changes in its social, economic and physical environments. In less than half a century, the country has been transformed from a nomadic and subsistence farming economy into a modern urban/industrial society with per capita income that is considered one of the highest worldwide. As a result, the demographics of the society have become more global and contemporary and international values and attitudes have impacted the existing cultural and architectural patterns. Qatari architectural trends have become increasingly contemporary and completely detached from the traditional ones that reflect the country's identity. Doha, the capital, has recently witnessed the resurgence of the discourse on Islam as a cultural identity. Sincerely at times, but opportunistically at others, many architects got engaged in the design of various historicist styles to satisfy the growing demand for a contemporary Islamic architecture. The modern and post modern Qatari architecture have gone their way disregarding tradition and as a result, the Qatari cultural Architectural traditional identity has been erased. Qatar's attractiveness today is generated from its modernized architectural patterns and styles that balance tradition-ism and modernism. Many of the newly designed buildings are strictly reproducing the Qatari traditional elements and styles as shown in Figure 2 [7].
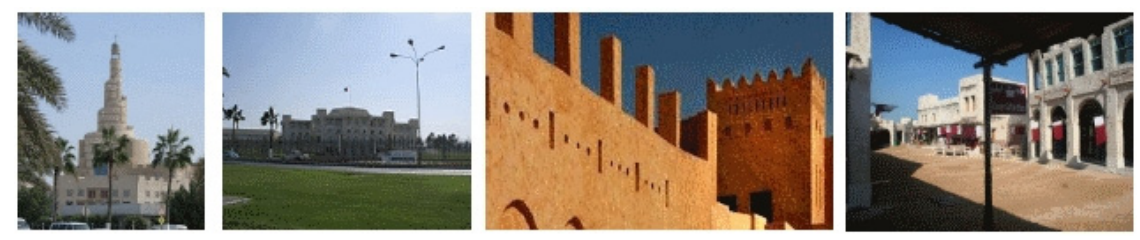

Figure 2: Modern buildings designed on Qatari traditional architectural patterns. 


\section{Scope of work}

In Qatar, contemporary western architecture becomes significant with a fast growth compared to the traditional trends, and the country has been transformed into a modern progressive urban with per capital incomes that are considered one of the highest incomes worldwide. The contemporary architecture have impacted the urban development and directed to be detached from the Qatari architecture language. Significant distracts in Doha bear witness to the struggle between culture, history and place making culminating in the question of a Qatari national identity. This concludes the first theoretical part of a running research project funded by Qatar National Research Fund - QNRF (http://www.qnrf.org). It develops the idea of developing indicators for unifying the Qatari architecture language and the contemporary architecture. A detailed theoretical study, are carried out to emphasize the architectural traditional elements that reflect the culture identity. This process is a part of presenting an introductory framework for unifying the Qatari architecture language in the urban contemporary environment with the support of city image and urban identity. The developed framework can facilitate urban identity for the groups associated with definite urban environments and play an important role in the formation, change, and reproduction of the identity of the place.

The next phase of the project is still on process and to be published in future. The second phase aims at applying the developed framework based on the developed framework for assessing Qatari architecture language in three contemporary case studies in Qatar.

\section{Contemporary architecture: the case of Qatar}

Today's awareness is about the environment and minimizing the use of energy. Subsequently today's architecture concerns the changes in the atmosphere and how to protect it. The trend wasn't negotiated in old architecture. This is because of using local building materials and trend that meet the environment. The buildings at this time are to build for last without harming the nature. An example is shown in Figure 3; Um Salal Mohammed fort, which is located in Qatar and was built using limestone as a local material.

Since Qatar has become an open country to the whole world, it has been affected by the changes in architecture. The huge development in Qatar a few

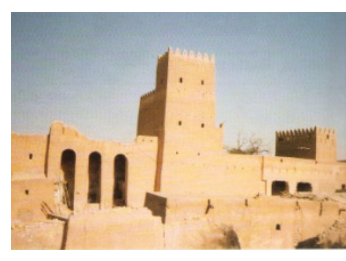

Figure 3: $\quad$ Um Salal Mohammed fort in Qatar.
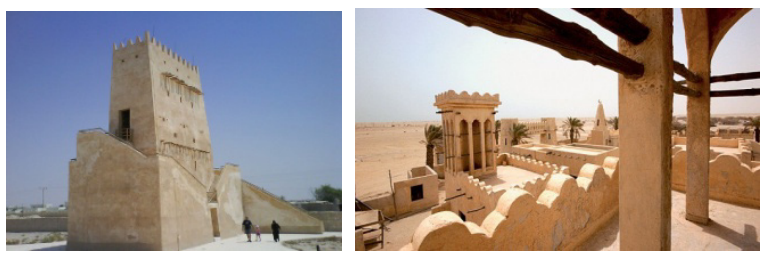
years ago increased the flow of people with different cultures and life styles. This variety of cultures in addition to the open market and globalization affect the style of architecture in Qatar. It becomes more open and accepts other cultures and had been expressed the latest building's technology. As a result, Qatar begun to emerge as a global center for media, education, culture and finance through huge investments and several initiatives such as the Al Jazeera Channel, the Doha Economic Zone, the Education City, Science and Community Development. A construction boom that erected skyscrapers, sport facilities, gated communities and iconic museums.

Therefore, the architecture in Qatar nowadays is a mix of European, Asian, Islamic, Arabian and local trends so that Qatar architecture image becomes difficult to be recognized (Figure 4).
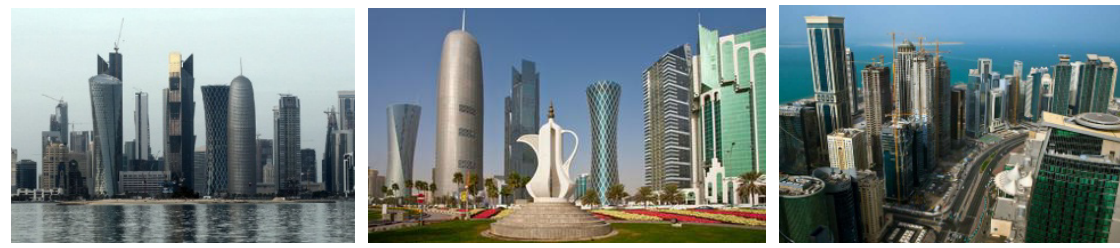

Figure 4: $\quad$ Contemporary architecture in Qatar - globalization trend.

However in the other direction, other traditional buildings are stringing the identity of the country (Figure 5). This direction goes with what Qatar Vision 2030 is about: Preserving Qatar's national heritage and enhance Arab and Islamic values and identity. Preserving its identity in all aspect and architecture is one of the major aspects of the vision. Qatar Vision seeks also to meet sustainability requirements and to be reflected in the contemporary architecture; keep the identity; use sustainable technology and materials and accordingly lead to good contemporary architecture [8].
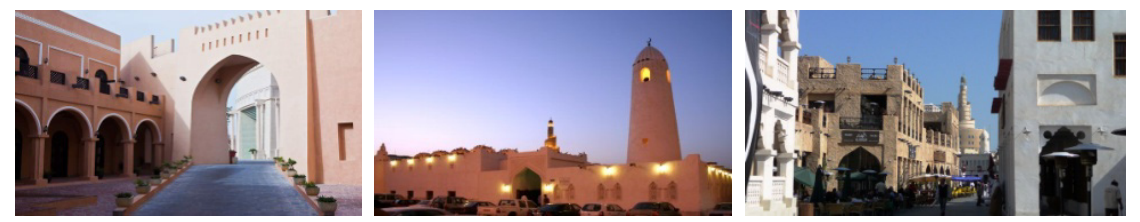

Figure 5: Traditional architecture in Qatar.

\section{Qatari traditional architecture language}

In this part, the significant traditional elements of Qatari architecture are to be identified. The aim of this part is to assess the contemporary architecture in Qatar in terms of integrating these elements. This is to be analyzed as an approach for applying the developed framework in the second phase of the UREP project (Qatari architecture language - case studies analysis). 


\subsection{Materials and building elements}

The traditional architecture in Qatar has its distinguished style that reflects the real taste of the people, who built the houses and of those who lived in them. The people of the region are governed by certain inherited social traditions. People are also bound by the prevailing environmental conditions, as regard to the building material that suit the climate. The building material and the climate are the main two factors that direct the way and decide the style of the building elements. The Qatari traditional architecture features is clear from the combination between the traditional materials and the different building elements as follows:

\subsubsection{The wooden beam}

The palm trunks and 'Danshall' wood stems are used to make bridges in the old traditional houses. The wooden bridges as shown in Figure 6 were made on top of the doors and window opining. They were also used to join the corners of the walls of the room. The use of the materials described above can be clearly seen with the very simple crossed pattern of bamboo canes directly on top of the mangrove pole beams supporting the roof.
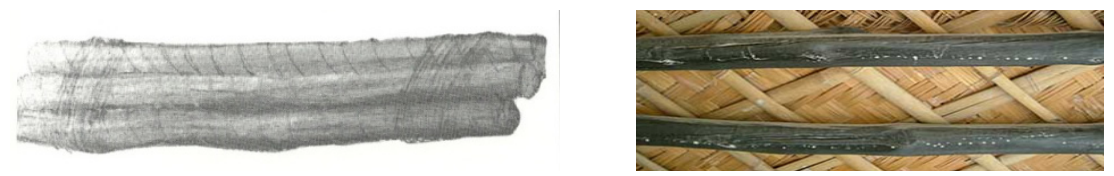

Figure 6: The use of wooden beams in the ceiling bridges (the Danshall).

\subsubsection{The traditional Qatari wall}

Ordinary natural mud is usually used while putting courses of strong and solid stone walls. The walls of the building are covered from inside and outside with mud, either by only mud or mixed with plants such as grass or hay to prevent cracks due to desiccation, rain water, wind and other atmospheric elements. The process of spoiling and disfiguring will continue as long as the remaining parts of the walls are left without maintenance and reinforcement (Figure 7).
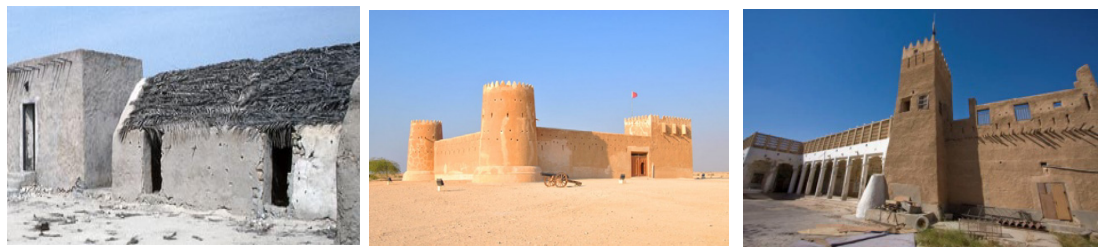

Figure 7: $\quad$ Some examples of mud wall in traditional Qatari architecture.

\subsubsection{The wind tower}

The wind tower was used in the past as a ventilation system that catches the air and distributed to the different spaces of the buildings. Wind tower was designed for use in dense urban situations where there was a need to draw air down into 
the courtyard houses. The wind towers were constructed on a square plan and contained a cruciform device on the internal diagonals which allowed air to funnel down into a space at the bottom of the tower (Figure 8).
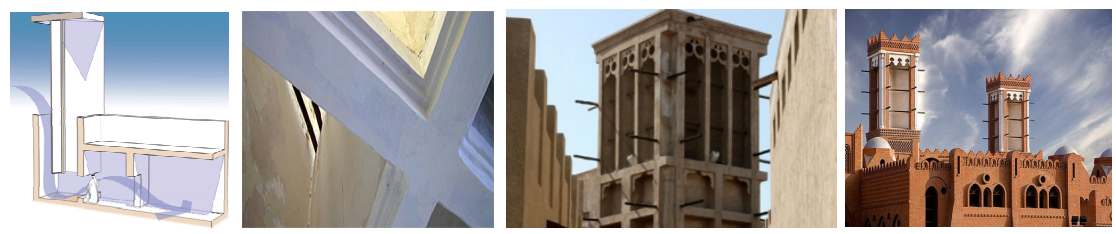

Figure 8: The idea and examples of wind tower in Qatari traditional buildings.

\subsubsection{Ornamental elements}

There are two main ornamental elements, which was used in traditional Qatari buildings during the centuries.

\subsubsection{Wall alcoves or recess}

They are horizontal wall cuttings made of carol bricks "fouroush" quarried from the sea shore. It was an economic and easy way and used for making wall opening for light and ventilation (wall air tower - wall badjair) (Figure 9).

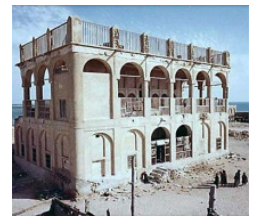

Figure 9:
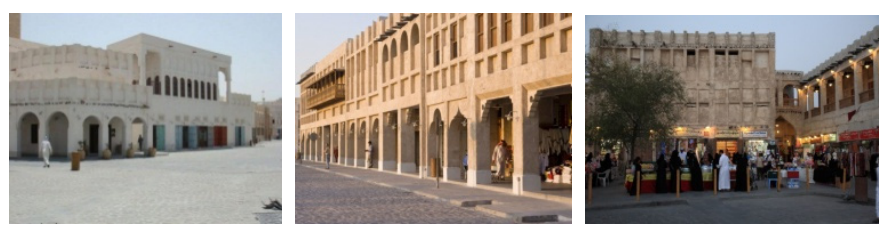

\subsubsection{Parapet and terraces}

All types of traditional buildings in Qatar were characterized by the presence of varied balconies on the tops of minarets, upper rooms and towers. These upper terraces were often compatible terraces with the kind and pattern of the building in Qatar which shows that such traditional architecture is completely characterized by these terraces (Figure 10).
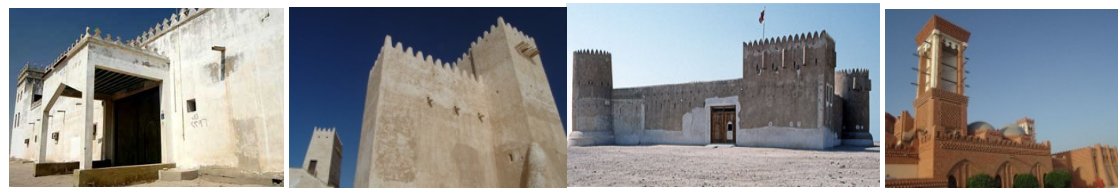

Figure 10: $\quad$ Parapet and terraces pattern in Qatari traditional architecture. 


\subsubsection{The openings}

The opening in Qatari traditional architecture consists of two building elements: the wooden doors and the windows. The significant details include the following.

\subsubsection{The wooden door}

Doors design and construction varied with time, cost and area, particularly in their rural or urban styles although. As would be expected, the wooden door is popular in Qatari traditional buildings. The best type of wood used for making doors is the sago palm wood. It is famous for its wooden door that carries plantlike and geometrical decoration. The design of doors and their doorways differed all over the Qatar peninsula dependent upon where their manufacture or craftsmen originated. In the construction over the door there are two more details. There is the standard ventilation solution above the door where the opening is protected by wrought iron bars set in the teak frame (Figure 11).
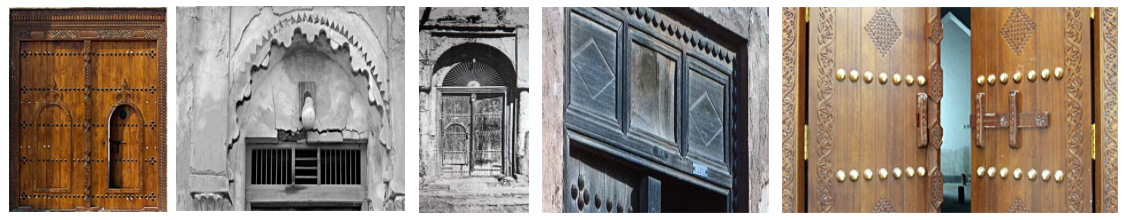

Figure 11: $\quad$ Some typical examples of Qatari traditional door.

\subsubsection{The windows}

The windows were rectangular recesses. They were one and half meters high, one meter width and $45 \mathrm{~cm}$ thick (it was almost the same thickness of the wall). All round the window from the outside, there was a wooden frame with a horizontal wooden board in the middle. This horizontal board divided the frame into two equal rectangles; one on the top and one below. Through the frame and the horizontal board there were some iron bars. The rows of windows in an old ruined building are typical in their size and positioning of those in many of the old buildings, particularly majaalis which are usually characterized by the open character of their walls (Figure 12).
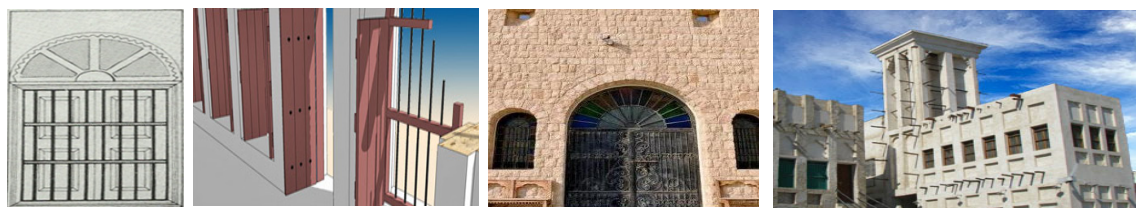

Figure 12: Traditional Qatari windows.

\subsection{Landscape components and activities}

Landscape elements draw the traditional sense in the spaces includes: lighting, signage, benches, and other amenities. They emphasis the traditional elements of 
architecture creating an essence of the old Qatari era; new features and sophisticated lighting systems are also developed to provide illumination (Figure 13) show Souk Waqif as a significant traditional example [7].
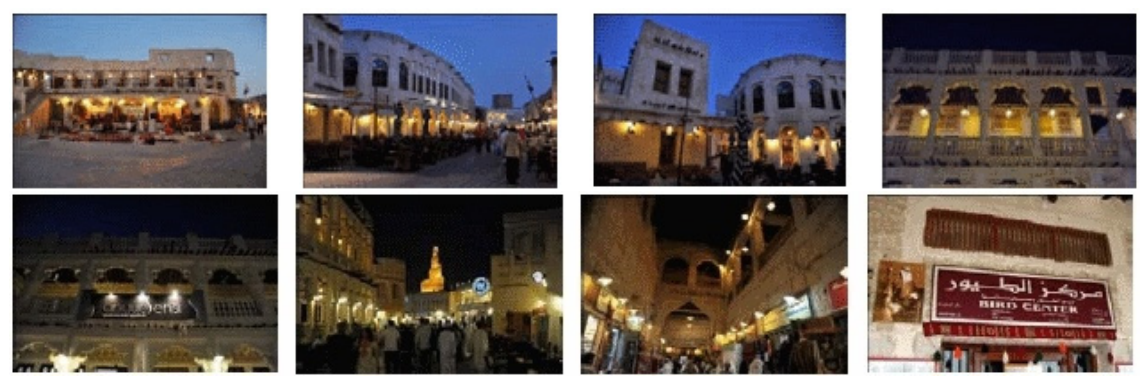

Figure 13: Souk Waqif: furniture, lighting and signage system.

\subsection{Function and activities:}

The existing of traditional activities such as galleries, workshops, art events and concert are also affecting the traditional value in the place. This is including art shops and exhibition rooms, souvenirs and restaurants serving a traditional cuisine.

\section{Establishing traditional architecture values- tabulation and analysis procedures}

The purpose of this part is to develop a check list of the indicators/parameters based on traditional architecture for integrating the Qatari architecture language in the urban contemporary environment with the support of city image and urban identity. Based on the previous theoretical study of Qatari architectural traditional elements, establishing architecture parameters that can be used in assessing the unifying of Qatari language with the contemporary architecture is to be established.

A framework is developed, taking into account the concluded elements/ parameters that affect the Qatari traditional value and based on the previous theoretical study. The traditional values are classified into three main parts: the building components, the function/ activities and landscape components as shown in Figure 14.

Building elements are providing as a guide to developers. They clearly identify the architectural elements and design features which reflect the Qatari architecture. The incorporation of these architectural elements and design features into the contemporary developments make a positive contribution to the unique character of the local architecture in Qatar.

Landscape components are a second parameter, which gives a lasting and often a sense of traditional and of the quality of development. Landscaping provides visual appeal and environmental comfort. It improves both the 
appearance and value of property and instills confidence and pride in the neighbourhoods. Landscape design involves a variety of elements that include both soft and hard surfaces, water, screening, fencing and lighting. Soft surfaces refer to live planting including trees, shrubs, grass and ground cover. Hard surfaces refer to non-live elements such as paved areas, stone, screening and edges. The integration of traditional landscape with a contemporary architecture is very effective in reflecting the sense of place and the identity of the country.

There is a relationship between activities and identity and in particular how activities can be used to promote the identity of the country. Traditional Qatari activities include horse racing, camel racing, and falconry is strengthen the sense of the place and reflects a fourth dimension of the identity of the place.

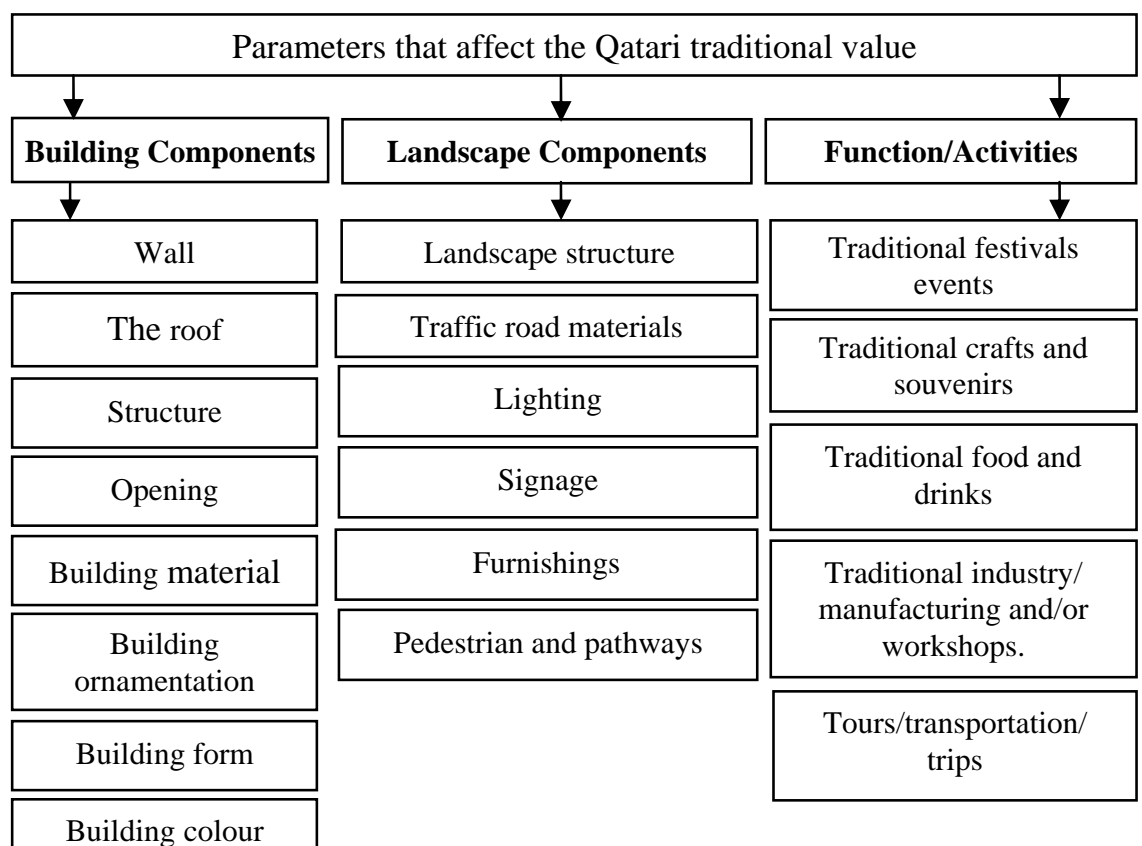

Figure 14: Parameters for Qatari traditional architecture.

\section{Future work}

A detailed review of the contemporary architecture in Qatar is to be carried out. This review demonstrates where 'Traditional Criteria' are available in the chosen application (traditional responsive contemporary trend). A questionnaire will be designed based on the produced values in Figure 14. The questionnaire is to be distributed to the experts and professionals in addition to the stockholders to measure the responses on the elements that reflect traditional responsive contemporary architecture. Three selected contemporary case studies in Doha are to be carried out for three significant different contemporary trends neighbourhoods: Al- Dafna, Souq Waqif, Pearl Qatar urban areas (Figure 15). 


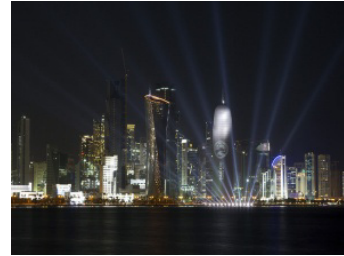

a) Al- Dafna Area

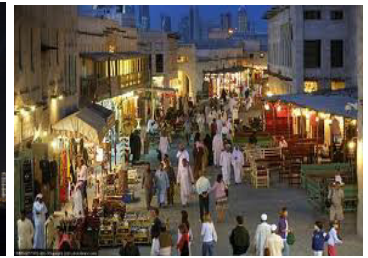

b) Souq Waqif

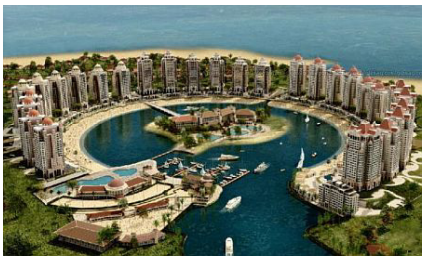

c) Pearl Qatar

Figure 15: Three selected case studies: Dafna, Souq Waqif and Pearl Qatar areas.

The limitation of the implemented framework and the outcome of the research are to be discussed. The results of the case studies demonstrate what was learned and what was gained in understanding the Qatari contemporary language. It might be advised to implement a scoring system of framework variables in kind of recommended interactive tools such as an agent, which enables local authorities, investors, and architects to have a conclusion concern the rank of unifying the Qatari architecture language and the contemporary architecture in Qatar.

\section{Conclusion}

Traditional architecture is a significant trend for fortifying the cultural identity. One of the main reasons for the attractiveness of Qatar is its ability to balance between the Qatari and the modern language in the contemporary architecture.

Many of Qatar's heritage buildings are magnificent in the sense that they were traditionally designed strictly according to the Qatari architecture trend. In recent years, Qatari urban has come to encompass a greater variety of western architectural styles. Some buildings are entirely distinctive and local in their character and many other buildings are the product of direct western architectural.

This paper presents indicators based on traditional architecture for integrating the Qatari architecture language in the urban contemporary environment with the support of city image and urban identity. These indicators are to be developed by exploring the specific characteristics of the contemporary architecture. The developed of the Qatari traditional elements based on a theoretical study is concluded.

The developed Qatari traditional elements are intended to cover key issues dealing with traditional architectural. This aims to adapting the past with the present and having a concluded image of the future. The traditional values are classified into three main parts: the building components, the function/activities and landscape components.

The future work is to be conducted by a technical review from decision makers and experts in the field, whom are well-versed and respected in the subject. The purpose of this stage is to review the implemented framework that 
can unify the Qatari architecture language and the contemporary architecture. It is also providing an evidence for the effectiveness of the established variables. This stage is allowing the necessary development and verification of the developed indicators.

\section{Acknowledgment}

This paper was made possible by an UREP award [UREP 11 - 019 - 5 - 004] from the Qatar National Research Fund (a member of The Qatar Foundation). The statements made herein are solely the responsibility of the author.

\section{References}

[1] Adham, K., Rediscovering the Island: Doha's Urbanity from Pearls to Spectacle (Chapter 9). Tradition, Modernity and Urban Development, ed. Y. El-Sheshtawy, pp. 218-257, 2008.

[2] QGSDP, Qatar National Development Strategy 2011 2016: Towards Qatar National Vision 2030, General Secretariat for Development Planning, 2011.

[3] Al-Buainain, F., Urbanisation in Qatar: A study of the Residential and Commercial Land Development in Doha City 1970-1997 Dissertation, University of Salford, 1999.

[4] Al-Kuwari, M. K., The Development of Doha and a Future Urban Strategy for Qatar, University College of Swansea, Wales, 1992.

[5] Alraouf, A.A., 2010, A New Paradigm in Knowledge-based Urban Development: From Knowledge to Creativity Economy, Qatar Urbanity Transformed. Proc. of the 3rd Knowledge Cities World Summit, eds. T. Yigitcanlar, P. Yates and K. Kunzmann, Melbourne, Australia: World Capital Institute, pp. 1273-1285, 2010.

[6] The World Bank - WB, Turning Qatar into a Competitive KnowledgeBased Economy: Knowledge Economy Assessment of Qatar, Doha, Qatar: The World Bank - Report to Qatar Planning Council, 2007.

[7] Ibrahim, H. and Khalil, R., Rooting Old Souk in the Contemporary Urbanism of Qatar, Spaces Flows: An International Journal of Urban and ExtraUrban Studies, 2(1), pp. 69-85, 2012.

[8] Qatar National Vision 2030, General Secretariat for Development Planning (GSDP), Virginia Commonwealth University in Qatar - Center for Research in Design, 2008. 